Artigo

\title{
Desterritorializando a aula de Matemática: o que pode um professor militante no âmbito de uma educação matemática menor?
}

\section{Desterritorializing the Mathematics class: what can a militant teacher in the context of a minor mathematics education?}

\section{Desterritorializando la clase de Matemáticas: ¿qué puede un profesor militante en el contexto de una educación matemática menor?}

\author{
João Paulo Risso ${ }^{1}$ \\ [0000-0002-0552-7034] \\ Thiago Donda Rodrigues ${ }^{2}$ \\ (iD) [0000-0002-3125-7779]
}

\begin{abstract}
Resumo
Este artigo objetiva vislumbrar linhas de fugas, intuir resistências e possibilidades outras para as aulas de Matemática. Para tal articulação, partiremos da noção de Educação Maior relacionando-a a Matemática Escolar e em contraposição, deslocando os conceitos de literatura menor de Gilles Deleuze e Félix Guattari e de educação menor de Silvio Gallo, discutiremos o conceito de educação matemática menor. Por fim, na última seção, apresentaremos uma possibilidade de prática em educação matemática menor. Destacamos que a educação matemática menor potencializa resistências aos mecanismos de controle social e a Matemática Escolar.
\end{abstract}

Palavras-chave: Educação matemática menor. Educação menor. Literatura menor. Professor militante. Educação Matemática.

\begin{abstract}
The aim of this article is to detect lines of leakage, to intuit resistances and other possibilities for Mathematics classes. For this articulation, we will start from the notion of Higher Education related to School Mathematics and in contrast, displacing the concepts of minor literature by Gilles Deleuze and Félix Guattari and minor education by Sílvio Gallo, we will discuss the concept of minor mathematical education. Finally, in the last section, we will present a possibility of practice in minor mathematics education. We emphasize that minor mathematical education increases resistance to social control mechanisms and School Mathematics.
\end{abstract}

Keywords: Minor mathematical education. Minor education. Minor literature. Teacher as militant. Mathematical Education.

\footnotetext{
1 joaormat@gmail.com, Licenciado em Matemática pela Universidade Federal de Mato Grosso do Sul (UFMS), campus de Paranaíba, Jaci/SP/Brasil.

2 thiago.rodrigues@ufms.br, Doutor em Educação Matemática, Professor do curso de Licenciatura em Matemática da Universidade Federal de Mato Grosso do Sul, campus de Paranaíba. Professor no programa de Pós-Graduação em Educação Matemática da UFMS de Campo Grande e do programa de Pós-Graduação em Educação da Universidade Estadual de Mato Grosso do Sul, Paranaíba/MS/Brasil.
} 


\section{Resumen}

Este artículo tiene como objetivo vislumbrar líneas de fuga, intuir resistencias y otras posibilidades para las clases de Matemáticas. Para esta articulación, partiremos de la noción de Educación Mayor relacionada con las Matemáticas Escolares y, en contraste, desplazando los conceptos de literatura menor de Gilles Deleuze y Félix Guattari y de educación menor de Sílvio Gallo, discutiremos el concepto de educación matemática menor. Finalmente, en la última sección, presentaremos una posibilidad de práctica en educación matemática menor. Destacamos que la educación matemática menor potencia la resistencia a los mecanismos de control social y las Matemáticas Escolares.

Palabras claves: Educación matemática menor; Educación menor; Literatura menor; Profesor militante; Educación Matemática.

\section{Introdução}

Aqui, os conceitos se acomodam uns aos outros, superpõem-se uns aos outros, coordenam seus contornos, compõem seus respectivos problemas, pertencem à mesma filosofia, mesmo se têm histórias diferentes.

(DELEUZE; GUATTARI, 1992, p. 30)

Inspirados pela epígrafe, este texto trata, principalmente, de três conceitos que pertencem a mesma filosofia: literatura menor, educação menor e educação matemática menor. Embora os dois últimos aparentemente refiram-se a um mesmo plano, é certo afirmar que os três compõem problemas distintos e possuem histórias diferentes.

Cronologicamente, o primeiro deles debruçou-se sobre um tipo específico de literatura, que vai na contramão da literatura hegemônica e transforma a maneira como estamos acostumados a ver e sentir. O segundo apresenta uma forma outra de educação, que faz ruir o institucional. O último deles, foco deste texto, tem emergido no território da Educação Matemática e ganhado corpo por meio do esforço de diferentes coletivos. Ele realiza, assim como os que o precedem, um questionamento ao dominante.

A filosofia a que tais conceitos pertencem é denominada de Filosofia da Diferença, a qual é considerada plural, e tal fato nos leva a destacar que tais conceitos pertencem à Filosofia da Diferença encarnada no pensamento de Deleuze, Guattari e Foucault. As Filosofias da Diferença têm origem no pós-estruturalismo, que segundo Peters (2000, p. 10) pode ser compreendido:

(...) como uma resposta especificamente filosófica ao status pretensamente científico do estruturalismo e à sua pretensão a se transformar em uma espécie de megaparadigma para as ciências sociais. [...] deve ser visto como um movimento que, sob a inspiração de Friedrich Nietzsche, Martin Heidegger e outros, buscou descentrar as "estruturas", a sistematicidade [...], criticando a metafísica que lhe estava subjacente e estendendo-o em uma série de diferentes direções, preservando, ao mesmo tempo, os elementos centrais da crítica que o estruturalismo fazia ao sujeito humanista.

Além disso, o pós-estruturalismo "adota uma posição antifundacionalista em termos epistemológicos e enfatiza um certo perspectivismo em questões de interpretação. [...] 
questiona o racionalismo e o realismo que o estruturalismo havia retomado do positivismo" (PETERS, 2000, p. 39).

Como destacado pelo autor supracitado, as Filosofias da Diferença têm como importante inspiração o pensamento de Nietzsche, com destaque para a sua crítica ao pensamento/ciência da modernidade. Um marco da mobilização dos conceitos e ideias nietzscheanas, remonta à segunda metade do século XX, principalmente a partir de 1960, na qual a intelectualidade parisiense se debruçou sobre a obra do filósofo, tal como se observa a seguir:

\begin{abstract}
A genealogia do pós-estruturalismo francês tem que ser compreendida, em parte, por suas filiações com o pensamento de Nietzsche. Em particular, com sua crítica da verdade e sua ênfase na pluralidade de interpretação; com a centralidade que ele concede à questão do estilo, visto como crucial, tanto filosófica quanto esteticamente, para que cada um se supere a si próprio, em um processo de perpétuo autodevir; com a importância dada ao conceito de vontade de potência e suas manifestações como vontade de verdade e vontade de saber. Esses temas filosóficos foram assumidos, adotados e experimentados pelos pós-estruturalistas franceses sob novas e estimulantes formas (PETERS, 2000, p. 32, grifos do autor).
\end{abstract}

Como visto, um ponto chave para a Filosofia da Diferença consiste na crítica da verdade. Nietzsche defende a não existência de verdades inatas, mas construções históricas e sociais, ou seja, "as verdades são construídas, fabricadas, inventadas em um determinado tempo, espaço e organização social para cristalizar uma ideia ou um conceito que se entende, ou se deseja que seja incontestável" (RODRIGUES, 2017, p. 06). Segundo Nietzsche (2007):

Um exército móvel de metáforas, de metonímias, de antropomorfismos, numa palavra, uma soma de relações humanas que foram poética e retoricamente intensificadas, transpostas e adornadas e que depois de um longo uso parecem a um povo fixas, canônicas e vinculativas: as verdades são ilusões que foram esquecidas enquanto tais, metáforas que foram gastas e que ficaram esvaziadas do seu sentido, moedas que perderam o seu cunho e que agora são consideradas, não já como moedas, mas como metal (NIETZSCHE, 2007, p. 36-37).

A partir disso, os filósofos da Filosofia da Diferença buscam pensar a diferença diferentemente do feito na filosofia da representação, que entende o diferente, a diferença como o divergente do similar, do idêntico. De outro modo, Deleuze $(2000$, p. 36) busca "pensar a diferença em si mesma e a relação do diferente com o diferente, independentemente das formas de representação que as conduzem ao Mesmo e as fazem passar pelo negativo". Para o filósofo:

A diferença não é o diverso. $O$ diverso é dado. Mas a diferença é aquilo pelo qual o dado é dado. É aquilo pelo qual o dado é dado como diverso. A diferença não é o fenômeno, mas o número mais próximo do fenômeno. Portanto, é verdade que Deus faz o mundo calculando, mas seus cálculos nunca estão corretos, e é mesmo esta injustiça no resultado, esta irredutível desigualdade, que forma a condição do mundo. O mundo "se faz" enquanto Deus calcula; não haveria mundo se o cálculo fosse correto (DELEUZE, 2000, p. 361). 
Nesse sentido, a diferença é tomada a partir da multiplicidade e se torna impossível de ser explicada, pois sempre que buscamos uma definição, mesmo que nos debrucemos aos ínfimos detalhes, sempre a faremos por aproximação. Sempre que nos propomos a explicar a diferença, acabamos fazendo a partir de um comparativo com o que é similar, mas a Filosofia da Diferença busca compreendê-la por ela mesma. "A diferença não é uma relação entre o um e o outro. Ela é simplesmente um devir-outro" (SILVA, 2002, p. 66).

Essa acepção de diferença é fundamental para esse texto pois entendemos que a as práticas da literatura menor, educação menor e/ou educação matemática menor estão sempre no intermezzo, no entre, nunca replicada, decalcada, é sempre rizoma, mapa.

Assim, em linhas gerais, este artigo busca, no contexto de uma discussão teórica, vislumbrar linhas de fugas $^{3}$ e intuir resistências e possibilidades outras para as aulas de Matemática. Para tal articulação partiremos da noção de Educação Maior relacionando-a a Matemática Escolar e em contraposição, deslocando os conceitos de literatura menor, de Deleuze e Guattari (1977), e de educação menor, de Gallo (2002; 2013), discutiremos o conceito de educação matemática menor. Este exercício busca corroborar outras propostas de teorizações em torno da obra de Deleuze e Guattari, como por exemplo em Clareto, Silva e Clemente (2013), Clareto (2013), Mondardo (2015), Gondim e Miarka (2017), Gondim e Miarka (2019), dentre outros. Por fim, apresentaremos uma prática em educação matemática menor.

\section{Abrindo a discussão: literatura menor, educação menor e professor militante}

Dá-me tua mão, amor a madrugada tem olhos que machucam e as ruas estão cobertas de pequenas estrelas anunciando que o passado sombrio caminha contra a liberdade do futuro.

A neblina tem olhos que delatam e noites sem pão nem flores querem de novo sentar à nossa mesa já tão farta de antigas dores.

(VAZ, 2016, p. 11)

Em busca de compreender como a estrutura educacional, a partir de mecanismos normalizadores, opera na transformação da criança em adulto e refletindo sobre possibilidades de resistência no interior dessa estrutura, Gallo (2002, 2013), a partir do conceito de literatura menor de Deleuze e Guattari (1977), realiza um deslocamento de conceito, visando operar a ideia de uma educação menor, que será a base central da proposta aqui empreendida.

\footnotetext{
3 "[...] as "linhas de fuga" nos guiam em direção ao Novo, ou seja, rumo ao não previsível, não preexistente. Nós não podemos dizer ao certo no que vai dar uma linha de fuga, principalmente porque ela não tem território e nem necessariamente uma linearidade no seu devir-acontecimento. Dessa forma, traçar linhas de fuga se apresenta então como ruptura, divisão e preparação para novas espacialidades e temporalidades" (MORAES; JARDIM, 2017, p. 25).
} 
Deleuze e Guattari propuseram o conceito de literatura menor como modo de analisar a obra de Franz Kafka, um autor judeu, nascido em Praga (capital da atual República Tcheca), que se apropriou de modo estratégico da língua alemã em tempos de dominação estrangeira, subverteu-a e construiu, a partir dela, uma literatura outra. Porém, "Uma literatura menor não é a de uma língua menor, mas antes a que uma minoria faz em uma língua maior" (DELEUZE; GUATTARI, 1977, p. 25). Além disso, uma literatura menor é marcada por três importantes características: a desterritorialização da língua, a ramificação política e o valor coletivo.

A compreensão do conceito de desterritorialização da língua pode ser auxiliada com a apresentação do conceito de território. Segundo Guattari e Rolnik (1986, p. 323)

[...] a noção de território aqui é entendida num sentido muito amplo, que ultrapassa o uso que fazem dele a etologia e a etnologia. Os seres existentes se organizam segundo territórios que os delimitam e os articulam aos outros existentes e aos fluxos cósmicos. O território pode ser relativo tanto a um espaço vivido, quanto a um sistema percebido no seio da qual um sujeito se sente "em casa". O território é sinônimo de apropriação, de subjetivação fechada sobre si mesma. Ele é o conjunto de projetos e representações nos quais vai desembocar, pragmaticamente, toda uma série de comportamentos, de investimentos, nos tempos e nos espaços sociais, culturais, estéticos, cognitivos.

Assim, em linhas gerais, a desterritorialização é um movimento pelo qual se abandona um território (não necessariamente um abandono literal) ou se produz um novo território a partir de um território anterior. Portanto, a desterritorialização da língua é um processo de subversão da língua central e desintegração de suas territorialidades bem definidas.

Ao subverter uma literatura maior, a literatura menor produz um ato político, tornase política, "Não que uma literatura menor traga necessariamente um conteúdo político expresso de forma direta, mas ela própria, pelo agenciamento que é, só pode ser política. Sua existência é política: seu ato de ser é antes de tudo um ato político em essência" (GALLO, 2002, p. 172)

$\mathrm{Na}$ literatura menor a coletividade predomina sobre as individualidades. A literatura adquire função de enunciação coletiva e revolucionária, desloca o artista de sua posição de centralidade e abre espaço para o protagonismo da comunidade como um todo:

A máquina literária substitui assim uma máquina literária futura, não inteiramente por razões ideológicas, mas porque somente está determinada a preencher as condições de uma enunciação coletiva que faltam em toda parte neste meio: a literatura tem a ver é com o povo (DELEUZE; GUATTARI, 1977, p. 27, grifos dos autores).

A partir da literatura menor e suas características, Gallo (2002) propõe o conceito de educação menor. Para tanto, o autor, por meio da Literatura Maior, lança mão da ideia de Educação Maior, que se constitui a partir "[...] dos planos decenais e das políticas públicas de educação, dos parâmetros e das diretrizes, [...] da constituição e da LDB, pensada e produzida pelas cabeças bem-pensantes a serviço do poder" (GALLO, 2002, p. 173), explicando de outro modo, "temos aí [na Educação Maior] toda uma produção de políticas públicas de educação, 
operando no contexto daquilo que Foucault denominou uma biopolítica, uma política de controle populacional" (GALLO, 2013, p. 9).

Assim, a Educação Maior é representada pelos sistemas de ensino, público ou privado, organizado pelo Estado, com todas as leis, regras, exigências, obrigações e deveres que os compõem.

De outro lado, a educação menor, para Gallo (2002, p. 173):

é um ato de revolta e de resistência. Revolta contra os fluxos instituídos, resistência às políticas impostas; sala de aula como trincheira, como a toca do rato, o buraco do cão. Sala de aula como espaço a partir do qual traçamos nossas estratégias, estabelecemos nossa militância.

Ao propor o conceito de educação menor, Gallo (2002) também desloca as três características das literaturas menores apresentadas anteriormente. Para o autor, na educação menor há a desterritorialização dos processos educativos, de forma a propiciar resistências aos controles exercidos pela Educação Maior e potencializar a aprendizagem:

Ora, se a aprendizagem é algo que escapa, que foge ao controle, resistir é sempre possível. Desterritorializar os princípios, as normas da educação maior, gerando possibilidades de aprendizado insuspeitadas naquele contexto. Ou, de dentro da máquina opor resistência, quebrar os mecanismos, como ludistas pós-modernos, botando fogo na máquina de controle, criando novas possibilidades. A educação menor age exatamente nessas brechas para, a partir do deserto e da miséria da sala de aula, fazer emergir possibilidades que escapem a qualquer controle (GALLO, 2002, p. 175).

Quanto à característica que se refere ao valor coletivo, implica percebermos que os processos da educação menor nunca são do âmbito individual. Na educação menor os atos singulares remetem a uma coletividade e os atos coletivos tornam-se singulares. Logo, os projetos sempre são coletivos e abertos. Assim, ao optar pela prática da educação menor, o professor "[...] estará escolhendo para si e para todos aqueles com os quais irá trabalhar. [...] não há a possibilidade de atos solitários, isolados; toda ação implicará em muitos indivíduos. Toda singularização será, ao mesmo tempo, singularização coletiva (GALLO, 2002, p. 176).

Assim como a literatura menor, a educação menor também tem a característica de ser um ato político, carrega consigo uma micropolítica, uma política do cotidiano, visto que ela não busca as grandes políticas, mas propõe resistências. No âmbito de sua política própria e sem preocupar-se com a instauração de uma falsa totalidade, a educação menor opera por rizoma, viabiliza "conexões e conexões; conexões sempre novas. Fazer rizoma com os alunos, viabilizar rizomas entre os alunos, fazer rizomas com projetos de outros professores. Manter os projetos abertos" (GALLO, 2002, p. 175-176). Deleuze e Guattari deslocaram o significado de rizoma atribuído pela botânica para pensar um sistema de pensamento e prática alternativo ao teorizado pela filosofia tradicional. Segundo os filósofos,

[...] diferentemente das árvores ou de suas raízes, o rizoma conecta um ponto qualquer com outro ponto qualquer e cada um de seus traços não remete necessariamente a traços de mesma natureza; ele põe em jogo regimes de signos muito diferentes, inclusive estados de não-signos. 0 
rizoma não se deixa reconduzir nem ao Uno nem ao múltiplo. Ele não é o Uno que se torna dois, nem mesmo que se tornaria diretamente três, quatro ou cinco etc. Ele não é um múltiplo que deriva do Uno, nem ao qual o Uno se acrescentaria $(n+1)$. Ele não é feito de unidades, mas de dimensões, ou antes de direções movediças. Ele não tem começo nem fim, mas sempre um meio pelo qual ele cresce e transborda. Ele constitui multiplicidades lineares a $\mathrm{n}$ dimensões, sem sujeito nem objeto, exibíveis num plano de consistência e do qual o Uno é sempre subtraído (n-1). Uma tal multiplicidade não varia suas dimensões sem mudar de natureza nela mesma e se metamorfosear. Oposto a uma estrutura, que se define por um conjunto de pontos e posições, por correlações binárias entre estes pontos e relações biunívocas entre estas posições, o rizoma é feito somente de linhas: linhas de segmentaridade, de estratificação, como dimensões, mas também linha de fuga ou de desterritorialização como dimensão máxima segundo a qual, em seguindo-a, a multiplicidade se metamorfoseia, mudando de natureza. Não se deve confundir tais linhas ou lineamentos com linhagens de tipo arborescente, que são somente ligações localizáveis entre pontos e posições (DELEUZE; GUATTARI, 1995, p. 31). ${ }^{4}$

Os autores ainda afirmam que o rizoma, um dos mais famosos conceitos da dupla, pode ser pensado a partir da ideia de mapa e platô:

O rizoma é uma antigenealogia. É uma memória curta ou uma antimemória. O rizoma procede por variação, expansão, conquista, captura, picada. Oposto ao grafismo, ao desenho ou à fotografia, oposto aos decalques, o rizoma se refere a um mapa que deve ser produzido, construído, sempre desmontável, conectável, reversível, modificável, com múltiplas entradas e saídas, com suas linhas de fuga. São os decalques que é preciso referir aos mapas e não o inverso. Contra os sistemas centrados (e mesmo policentrados), de comunicação hierárquica e ligações preestabelecidas, o rizoma é um sistema a-centrado não hierárquico e não significante, sem General, sem memória organizadora ou autômato central, unicamente definido por uma circulação de estados. O que está em questão no rizoma é uma relação com a sexualidade, mas também com o animal, com o vegetal, com o mundo, com a política, com o livro, com as coisas da natureza e do artifício, relação totalmente diferente da relação arborescente: todo tipo de "devires". Um platô está sempre no meio, nem início nem fim. Um rizoma é feito de platôs. Gregory Bateson serve-se da palavra "platô" para designar algo muito especial: uma região contínua de intensidades, vibrando sobre ela mesma, e que se desenvolve evitando toda orientação sobre um ponto culminante ou em direção a uma finalidade exterior. (DELEUZE; GUATTARI, 1995, p.32).

Ao aprofundar a discussão, Gallo (2013) apresenta-nos algumas variações em torno da educação menor, as quais são: (i) educação menor como outra escola - construção de outra escola, sem buscar criar um modelo ou ser dominante; (ii) educação menor: o fora dentro da escola - na invenção coletiva dos alunos e professores, que mesmo situados em uma

\footnotetext{
${ }^{4}$ Tem-se uma interessante explicação do conceito de rizoma em "O Estranho Conceito de um Rizoma”, disponível em <https://www.youtube.com/watch?v=fOYnCY7myDM>.
} 
instituição escolar, engendram um fora da escola por não reproduzirem os padrões estabelecidos; (iii) educação menor para além da escola - segundo o autor, esta variação pode ser considerada a mais radical, pois "recusa a forma escola, por compreender que ela, como modelo de dominação, não permite a proliferação de variedades" (Ibidem, p. 9); (iv) educação menor: resistências e heterotopias no cotidiano escolar - neste último contorno, a partir do conceito foucaultiano de heterotopia, somos convidados a "pensar o cotidiano escolar como um outro espaço, um outro lugar, em que outras relações sejam possíveis, em que a criação seja possível. Não local de permanência, mas lugar de passagem, entre lugar" (Ibidem, p. 10).

Ao professor que opta pela prática da educação menor, Gallo (2002) dá o nome de professor militante. Mas afinal, o que vem a ser um professor militante? 0 autor faz emergir essa figura por meio de outro conceito: o professor profeta. Para o autor, eram características do professor profeta ser crítico, consciente de seu papel social e político, alguém que, "vislumbrando a possibilidade de um novo mundo fazia a crítica do presente e procurava apresentar, então, a partir da crítica do presente, a possibilidade de um mundo novo. O professor profeta é alguém que anuncia as possibilidades, alguém que mostra um mundo novo" (Ibidem, p. 171). A diferença entre o professor profeta e o professor militante é sutil, porém, extremamente potente:

[...] [o professor militante] seria não necessariamente aquele que anuncia a possibilidade do novo, mas sim aquele que procura viver as situações e dentro dessas situações vividas produzir a possibilidade do novo. Nesse sentido, o professor seria aquele que procura viver a miséria do mundo, e procura viver a miséria de seus alunos, seja ela qual miséria for, porque necessariamente miséria não é apenas uma miséria econômica; temos miséria social, temos miséria cultural, temos miséria ética, miséria de valores. Mesmo em situações em que os alunos não são nem um pouco miseráveis do ponto de vista econômico, certamente eles experimentam uma série de misérias outras. O professor militante seria aquele que, vivendo com os alunos o nível de miséria que esses alunos vivem, poderia, de dentro desse nível de miséria, de dentro dessas possibilidades, buscar construir coletivamente (Ibidem, p. 171, grifo do autor).

Assim, os conceitos de literatura menor, educação menor e professor militante criam possibilidades de pensarmos uma educação matemática outra, bem como alternativas de enfrentamento dos mecanismos de controle que atravessam o sistema educacional. Por isso, questionamos: qual seria a potência de pensar a educação matemática como uma arte menor, uma educação matemática menor?

\section{Por uma educação matemática menor}

Escrevo porque ouço vozes, umas gritam de coragem, outras de medo, e todas elas agitam em silêncio o meu coração.

Nada a ver com gramática, estética, ética ou métrica, escrevo porque em mim

a palavra é fio desencapado, 
é elétrica.

A polícia acadêmica, quando enquadra, não sabe ou esqueceu que as ruas gritam livres ainda que durma na calçada

(VAZ, 2016, p. 138)

Como mencionado em outros momentos deste texto, a Educação Maior busca normalizar e docilizar os indivíduos, a intenção não é a sua sujeição, mas a fabricação de corpos submissos e exercitados, que tenham suas forças do corpo aumentadas em termos econômicos de utilidade e diminuídas em termos políticos de obediência (FOUCAULT, 2005), ou seja, pretende-se fabricar um indivíduo que tenha sua produtividade maximizada, mas com resistência minimizada e limitações acerca da reflexão crítica.

A Matemática Escolar é um dos mecanismos utilizados pela escola para a produção do sujeito, bem como também exerce funções dentro de outros mecanismos que têm o mesmo fim. Na escola, a disciplina Matemática representa, ou ao menos busca representar, a ciência Matemática ${ }^{5}$, representa a "ciência régia"; talvez, por isso, ela seja superestimada não só no ambiente escolar mas também fora dele, sendo comum ouvirmos que a Matemática é a disciplina "mais importante", "mais difícil", "para poucos", "para os melhores". Além disso, a Matemática Escolar e a forma como geralmente é ensinada tendem a separar os bons dos maus alunos, os inteligentes dos poucos inteligentes, geralmente costuma eleger os que poderão alcançar bons cargos, e fadar a cargos e profissões com menor remuneração os que não se saem bem com Ela... Por essas características, é possível ponderarmos que a "Matemática Escolar [...] pode rotular, marcar, classificar, marginalizar, codificar, controlar, comparar, penalizar, diferenciar, hierarquizar, homogeneizar, mecanizar, excluir..."(RODRIGUES, 2017, p. 17)

Nossa crítica em relação à Matemática Escolar não está somente ao nível da didática, mas também diz respeito aos âmbitos social, cultural, econômico e político, pois, a partir do entendimento de que a Matemática Escolar, como representante da "Ciência Régia", está fundada em verdades inatas, ela exclui qualquer possibilidade de reconhecimento de outras matemáticas, de outras formas de pensar, de outras lógicas, ela reforça também a existência de uma cultura superior, de um modo de pensar superior, etc. Nesse sentido, a Matemática Escolar impossibilita a criação e a emergência do novo, de matemáticas outras, pois sempre exige a reprodução do mesmo.

Com vistas a problematizar possibilidades de resistência às forças homogeneizantes e normalizantes da Matemática Escolar, deslocamos as três características da educação menor (desterritorialização dos processos educativos, ramificação política e o valor coletivo), bem como as variações conceituais do trabalho de Gallo (2013), para construirmos contornos de uma educação matemática menor.

Ao deslocarmos a primeira característica da educação menor produzimos a primeira marca de uma educação matemática menor: a desterritorialização dos processos educativos em matemática - processo que implica na saída do território da Matemática Escolar e reterritorialização na educação matemática menor, ou seja, implica na produção de um modo

${ }^{5}$ Também usaremos para nos remeter à ciência Matemática apenas “Matemática”. 
outro de pensar e praticar a educação matemática a partir do território da Matemática Escolar, trata-se da transição e subversão pelas/das fronteiras de tal território.

Assim, para desterritorializar a Matemática Escolar, o professor militante cria uma ação de desordem, de fragmentação, para buscar novos saberes e práticas, não instituídos, alternativos, livres de qualquer controle, imaginativos, singulares. Essa desterritorialização realiza um deslocamento do enfoque único no caráter pedagógico, abre espaço para que o profissional aborde questões invisibilizadas nas aulas de Matemática.

De outro lado, podemos perceber a ramificação política da educação matemática menor quando, por exemplo, em relação à Matemática Escolar ou/e à Acadêmica, o professor de Matemática militante problematiza suas supostas neutralidades e de seu ensino, critica a imposição dessas como verdades incontestáveis, cria possibilidades de aprendizagens matemáticas não normalizadoras, ou discute e cria resistência aos mecanismos de exclusão por meio delas, ou ainda, questiona o monopólio universalizante da Matemática Escolar que muitas vezes apaga outras formas de matematizar, dentre muitas outras possibilidades. Assim, a educação matemática menor preocupa-se com a esfera política e o professor busca apoiar lutas de grupos oprimidos e excluídos do tecido social, não fecha os olhos diante das injustiças e combate o discurso apolítico e higienizador que paira os processos educativos.

Essas questões são corroboradas quando, a partir do valor coletivo como característica da educação matemática menor, o professor militante suscita discussões de múltiplas naturezas, tais como a quem interessa as aulas de Matemática e quais demandas elas se preocupam em atingir. O que comumente vemos é um alinhamento das aulas de Matemática com um sistema que constantemente explora e pouco se preocupa com a multiplicidade da existência. Para tal, na maioria das vezes, a aula Matemática é desenvolvida de modo a não considerar as demandas dos coletivos sociais, atendo-se majoritariamente às demandas neoliberais. Por exemplo: Quantos dos que estão lendo este texto teve uma aula de Matemática que problematizava o machismo ou a homofobia ou a transfobia ou algum dos outros muitos preconceitos? Quantos assistiram aulas de Matemática antirracistas? Quantos resolveram um problema de Matemática que retratava a desigualdade social? Quantos dos leitores tiveram suas demandas levadas em consideração nas aulas de Matemática que participaram? Um professor de Matemática militante que visa pensar suas aulas em uma perspectiva menor buscará planejá-las sob o enfoque dos anseios dos múltiplos coletivos da sociedade, distanciando-se da postura individualizante do sistema em que vivemos.

Uma outra discussão suscitada pelo valor coletivo, atrelada a anterior, reside no âmbito curricular. Os currículos, em particular os de Matemática, são currículos coletivos? Ou ainda, de outro modo: todos os sujeitos que eles atingem participam de sua construção? 0 estudante tem voz na sua elaboração? Raramente!

Os currículos de matemática, exceto raras exceções, são verticais, hierarquizantes, arbóreos, tendem a serem homogeneizantes, impedem a proliferação de diferenças e excluem de sua elaboração dois dos principais sujeitos escolares: os professores e os estudantes. Pensar o valor coletivo da educação matemática menor possibilita, também, fazer estremecer as estruturas dos currículos de matemática, torná-los abertos à experiência, à inventividade, e à construção conjunta entre professor (militante), estudantes e outros possíveis sujeitos escolares e não escolares. Porém, não se trata de criar currículos gerais, modelos, ao contrário, trata-se da construção coletiva de currículos locais, provisórios, que abarquem anseios e demandas do contexto e do tempo de seus múltiplos criadores. 
Por sua vez, o deslocamento da primeira variação da educação menor encontrado em Gallo (2013), que de certo modo indica uma desterritorialização, possibilita pensarmos uma educação matemática outra, o que implica opor resistência aos padrões dominantes da Matemática Escolar, por meio da criação de linhas de fuga para a emergência de formas outras de educação matemática.

As propostas pedagógicas em Educação Matemática (Etnomatemática, Educação Matemática Crítica, Modelagem Matemática, Tecnologias Digitais, interfaces entre Artes e Matemática, dentre outras) historicamente demarcaram rupturas em relação ao ensino pautado na Matemática Escolar, produziram expressões de educações matemáticas menores, visto que subverteram/subvertem "de dentro, as normas, o currículo, o conteúdo formalmente proposto para a escola, para a rede, para o sistema [para o ensino de matemática]" (PRADO-NETO, 2013, p. 13).

Porém, alguns usos e teorizações referentes a essas propostas pedagógicas foram capturadas - e se deixaram capturar - pela Educação Maior e pela Matemática Escolar, e assim fizeram com que perdessem sua força subversiva e inventiva, bem como se distanciaram de suas propostas iniciais. Esse processo consiste na transformação de expressões nômades de educações matemáticas em aparelhos de Estado (SILVA; MIARKA, 2017).

As possibilidades de educações matemáticas menores são múltiplas e vão além das propostas pedagógicas. Na produção de educações matemáticas menores pelos professores militantes e estudantes estão em jogo forças inventivas, forças que criam mundos, forças que tensionam e questionam a dogmatização e mesmice da Matemática Escolar.

No segundo deslocamento temos a produção do fora dentro da aula de matemática. Esse contorno relaciona-se intimamente com a atuação do professor militante em parceria com os alunos, pois trata-se de criar um fora dentro da aula de matemática, por meio do distanciamento das palavras de ordem e delimitações da Educação Maior e da Matemática Escolar. O que entra em ação é a produção coletiva da aula de matemática, considerando-se as singularidades dos alunos e o que há para além da aula de Matemática.

Ao ceder espaço para o fora da aula de Matemática, que a Matemática Escolar insiste em manter distante, o professor militante dessa disciplina possibilita e reforça a liberdade criativa de experimentações e articulações coletivas entre/com elementos matemáticos e não-matemáticos, visto que insistir na prática higienista da Matemática Escolar, que desconsidera importantes elementos culturais, sociais e políticos presente na vida dos educandos, só tende a limitar a própria aprendizagem matemática.

Já o terceiro contorno, educação matemática menor para além da escola, remete-se à negação da forma escola, e consequentemente do que se denomina disciplina de Matemática, "por compreender que ela, como modelo de dominação, não permite a proliferação de variedades" (GALLO, 2013, p. 9). O fim da disciplina Matemática como tradicionalmente a conhecemos pode ser visto em algumas poucas experiências nacionais e internacionais - Escola da Ponte em Portugal e Projeto Âncora no Brasil são dois exemplos - , porém são escolas que buscam fugir do modelo normalizador imposto pelo Estado, no entanto, na grande maioria das escolas o que se tem por opção ou imposição é um trabalho dentro da Educação Maior e da Matemática Escolar, mas que nos exige um trabalho de resistência, um trabalho de militância. 


\section{Uma prática em educação matemática menor}

Deus que me perdoe, mas não quero ir para o céu.

Porque todas as pessoas que transformam essa vida num inferno dizem que também vão para lá.

(VAZ, 2016, p. 150)

Nesta seção apresentaremos o que pode se configurar como uma prática ${ }^{6}$ em educação matemática menor desenvolvida com duas turmas do terceiro ano do Ensino Médio, de uma escola pública do município de Paranaíba-MS, vinculada ao Programa Institucional de Bolsas de Iniciação à Docência (PIBID) do curso de Matemática-Licenciatura da Universidade Federal de Mato Grosso do Sul, campus de Paranaíba. Nossa intenção não é fornecer um modelo de como as práticas em educação matemática menor devem ocorrer. Não queremos apresentar a verdade, visto que as mesmas não seguem padrão, não são passíveis de reprodução, não são decalcáveis; ao contrário, por serem rizomas, são singulares, são mapas e atendem demandas locais. Assim, o objetivo é que esse relato possa inspirar o leitor que queira desenvolver práticas de educação matemática menores com seus alunos.

Como visto nas seções anteriores, a educação matemática menor ocorre de dentro da Matemática Escolar, ela é fruto da desterritorialização da Matemática Escolar através da ação do professor militante. Sendo assim, esta proposta se desenvolveu a partir da desterritorialização do jogo Contador Imediato, proposto por Smole, Diniz e Milani (2007). Com a classe dividida em grupos compostos por 6 ou 7 alunos, lançou-se o convite para jogarem cinco rodadas do jogo, tal como as autoras propõem:

\section{Regras}

1. O jogo consiste de cinco jogadas.

2. Decide-se quem começa.

3. Os jogadores alternam-se nas jogadas.

4. Cada jogador, na sua vez, escolhe um dos números do quadro, que não poderá mais ser escolhido por outro jogador, e faz a opção por dividi-lo por 10, 100 ou 1000.

5. Verifica em que caixa de pontos está o resultado $R$ da divisão escolhida e marca os pontos obtidos.

6. Durante uma partida (cinco jogadas), cada jogador deve realizar pelo menos uma divisão por 10, 100 e 1000.

7. Ganha o jogador que, ao final, tiver o maior total de pontos.

Fonte: Smole, Diniz e Milani (2007)

\footnotetext{
${ }^{6}$ Uma primeira versão da adaptação desta atividade foi desenvolvida pelo acadêmico Flávio Luz como atividade avaliativa da disciplina "Prática de Ensino em Matemática III", ministrada pelo segundo autor deste artigo, no curso de Matemática-Licenciatura da Universidade Federal de Mato Grosso do Sul, Campus de Paranaíba.
} 


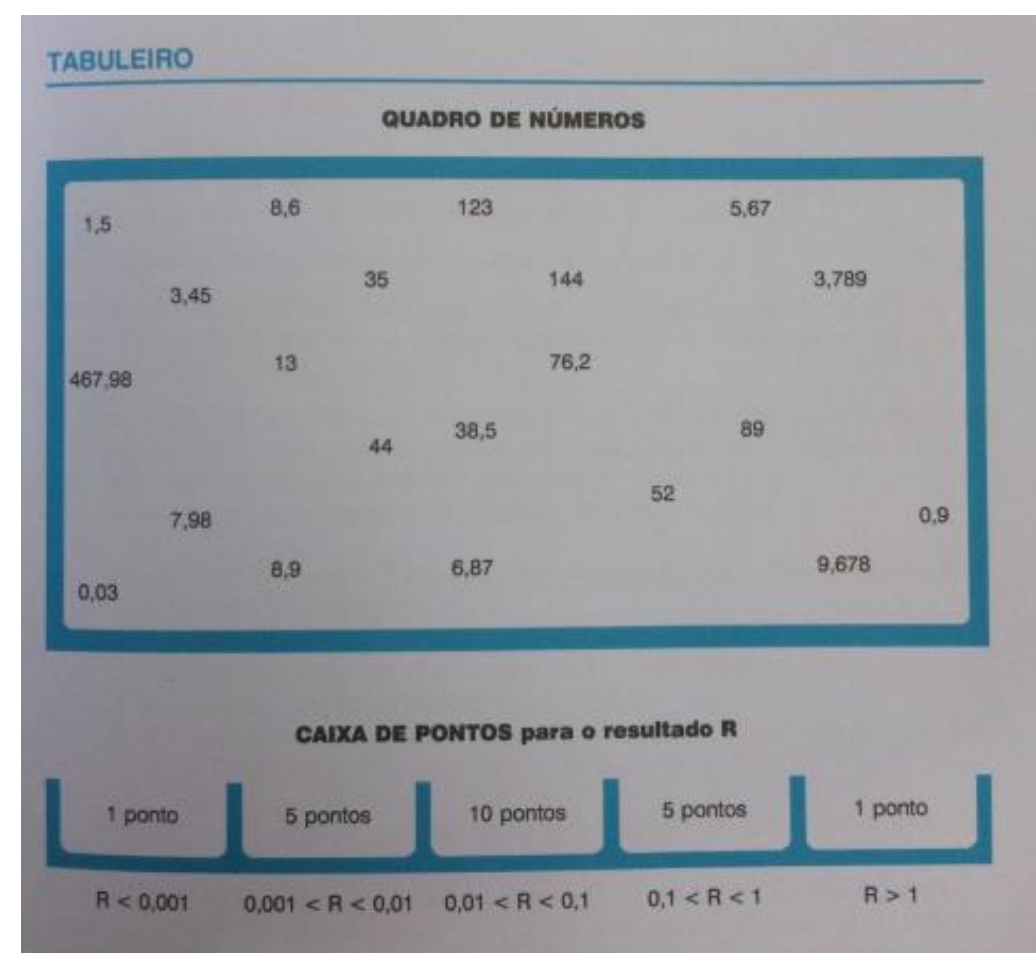

Figura 1: Tabuleiro do jogo Contador Imediato Fonte: Smole, Diniz e Milani (2007)

Após esta primeira etapa da atividade, colocamos em ação a desterritorialização dos processos educativos em matemática, visto que os alunos deveriam jogar novamente o jogo 'Contador Imediato', porém, além das regras originais, acrescemos a seguinte regra: por meio de sorteio, um aluno de cada grupo começaria o jogo com 50 pontos, dois alunos começariam com 20 pontos e os demais alunos com 0 pontos. Quando todos os grupos finalizaram as rodadas, verificou-se que dentre os nove grupos, apenas um deles teve como vencedor um jogador que iniciou com 20 pontos e apenas um grupo teve como vencedor uma aluna que iniciou com 0 pontos. Nos demais grupos, os vencedores tinham iniciado com 50 pontos.

Nesta segunda etapa objetivava-se que, a partir da experiência de competirem em um jogo com uma desvantagem inicial, com as dificuldades e os problemas e dificuldade enfrentados pelos jogadores que iniciavam com menos pontos, os alunos pudessem refletir sobre essa situação de jogo e relacioná-la com a questão da desigualdade de renda e de riquezas em nosso país, bem como o problema da meritocracia. Desse modo, após terminarem essa etapa, foram apresentados dados referentes às desigualdades sociais no Brasil e iniciou-se uma discussão sobre o tema a partir da atividade. No decorrer da apresentação dos dados estatísticos sobre a situação social, econômica e política brasileira, foram percebidos sentimentos de surpresa e repulsa frente às informações transmitidas. Tais sentimentos acentuaram-se, sobretudo, entre o grupo de alunos que exerciam, na época, alguma atividade remunerada, quando foram apresentados dados estatísticos sobre distribuição de renda, tal como este: que um indivíduo que ganha um salário mínimo mensalmente necessitaria trabalhar 19 anos para ganhar o equivalente a um mês de renda média do 0,1\% mais rico da população brasileira (OXFAM, 2017).

Essa atividade buscou contribuir com o debate e enfrentamento da desigualdade de renda e riqueza do Brasil visto que os dados nacionais e internacionais são alarmantes. Um relatório sobre desigualdade social, publicado pela Oxfam Brasil em 27 de setembro de 2017, 
e intitulado $A$ distância que nos une, revela em detalhes a disparidade socioeconômica existente no Brasil, permeando inclusive análises por gênero e etnia. O relatório aponta estatísticas lastimáveis: $01 \%$ mais rico da população brasileira recebe, em média, mais de $25 \%$ de toda a renda nacional; $5 \%$ da população - os mais ricos - recebem, por mês, o mesmo que os demais $95 \%$ juntos; seis brasileiros têm uma riqueza equivalente ao patrimônio dos 100 milhões mais pobres do país. Caso seja mantida a tendência dos últimos 20 anos, a Oxfam Brasil calcula que mulheres terão equiparação salarial com os homens somente em 2047, e a equiparação da renda média dos negros com a dos brancos ocorrerá somente em 2089, dentre outras. Tais dados mostram ser imprescindível adotarmos uma postura militante no trabalho em sala de aula, bem como fica evidente que a atividade apresenta uma ramificação política muito necessária e urgente, bem como têm seu valor coletivo, visto que incide sobre a vida de milhões de brasileiros.

\section{Considerações finais}

Ao adentrarmos as linhas finais deste artigo, importante se faz ressaltarmos que a educação matemática menor tem a potência de mobilizar aprendizagens coletivas e reconhecer os (des)caminhos empreendidos pelos alunos, pelos quais "atravessam várias fronteiras e margens, falam diversas línguas, recriam outras possibilidades que aquelas doutrinas [como a Matemática Escolar], [...] a possiblidade que vale é a hibridizada por eles e, portanto, não oficial" (SOUZA, 2013, p. 213, grifos do autor). Aprender e produzir o novo coletivamente, bem como defender as multiplicidades que permeiam o cotidiano escolar, contribui com o enfrentamento das palavras de ordem e dos mecanismos de controle relacionadas ao (bio)poder disciplinar e engendra um devir-resistência e...

Devido a sua dinâmica rizomática, que se aproxima da noção de rede (não como teia geométrica) proposta por Souza (2013), a educação matemática menor mobiliza-nos a pensar a aprendizagem (e a pesquisa) como experiência. A experiência potencializa abertura, não reforça modelos e roteiros, questiona discursos dominantes e normalizadores, ataca as engrenagens dos mecanismos de controle, dificulta capturas pelo Estado, nos coloca em movimento com o imprevisível e em exercício constante de estranhamento e questionamento das verdades que nos atravessam e nos subjetivam.

\section{Referências}

CLARETO, Sônia Maria; SILVA, Aline Aparecida da; CLEMENTE, João Carlos. De Triângulo a bola: uma matemática menor e a sala de aula. In: XI Encontro Nacional de Educação Matemática, 2013, Curitiba. Educação Matemática: retrospectivas e perspectivas. Rio de janeiro: Sociedade Brasileira de Educação Matemática, 2013. v. 01. p. 01-12.

CLARETO, Sônia Maria. Matemática como acontecimento na sala de aula. In: 36a Reunião Anual da Anped, 2013, Goiânia. Sistema Nacional de Educação e Participação Popular: Desafios para as Políticas Educacionais. Rio de Janeiro: Anped, 2013. v. 01. p. 01-15.

DELEUZE, Gilles. Diferença e repetição. Lisboa, Portugal: Relógio D’Agua, 2000. 
DELEUZE, Gilles e GUATTARI, Félix. Kafka - por uma literatura menor. Rio de Janeiro: Imago, 1977.

DELEUZE, Gilles e GUATTARI, Félix. O que é a filosofia? Rio de Janeiro: Ed. 34, 1992.

DELEUZE, Gilles e GUATTARI, Félix. Mil platôs - capitalismo e esquizofrenia, vol. 1. Rio de Janeiro: Ed. 34, 1995.

FOUCAULT, Michel. Vigiar e punir: nascimento da prisão. Trad. Raquel Ramalhete. 30. ed. Petrópolis: Vozes, 2005.

GALLO, Silvio. Em torno de uma educação menor. Educação e Realidade. Porto Alegre, v. 27, n. 2, p. $169-178,2002$.

Em torno de uma educação menor: variáveis e variações. In: 36a Reunião Nacional da ANPEd, 2013, Goiânia. Sistema Nacional de Educação e Participação Popular: desafios para as políticas educacionais. Goiânia: ANPEd, 2013. p. 1-12.

GONDIM, Diego Matos; MIARKA, Roger. A Constituição de um Plano de Intensidades: aprender e matemática e diferença e escrita-avalanche e... PERSPECTIVAS DA EDUCAÇÃO MATEMÁTICA, v. 10, p. 115-131, 2017.

GONDIM, Diego Matos; MIARKA, Roger. Uma comunidade dos cantos: notas de uma experiência em campo como expressão de uma educação (matemática) dos sentidos. REVISTA DE HISTÓRIA DA EDUCAÇÃO MATEMÁTICA, v. 5, p. 100, 2019.

GUATTARI, Félix; ROLNIK, Suely. Micropolítica: cartografias do desejo. Petrópolis: Vozes, 1986.

MONDARDO, Marcos Leandro. O território como ferramenta analítica no ensino de Geografia: dos dispositivos de controle à produção de multi/transterritorialidades. Revista Brasileira de Educação em Geografia, v. 5, p. 122-139, 2015.

MORAES, Daniel Silva; JARDIM, Alex Fabiano Correia. O que é uma linha de fuga? Consideração a partir do conto "A terceira margem do rio", de Guimarães Rosa. VISO: CADERNOS DE ESTÉTICA APLICADA, v. 01, p. 16-30, 2017

NIETZSCHE, Friedrich Wilhelm. Sobre verdade e mentira no sentido extra-moral. São Paulo, SP: Hedra, 2007.

OXFAM. A Distância que nos une. OXFAM Brasil, 2017. Disponível em: <oxfam.org.br/umretrato-das-desigualdades-brasileiras/a-distancia-que-nos-une/>. Acesso em: 18 mai. 2020.

PETERS, Michael. Pós-estruturalismo e filosofia da diferença: uma introdução. Belo Horizonte, MG: Autêntica, 2000. 
PRADO-NETO, Manuel. Desterritorializações Docentes: casos de uma educação menor. 2013. 111 f. Dissertação (Mestrado em Educação) - Programa de Pós-Graduação em Educação, Universidade Tiradentes, Aracaju, 2013.

RODRIGUES, Thiago Donda. Etnomatemática e Filosofia da Diferença: Possíveis Diálogos. JOURNAL OF MATHEMATICS AND CULTURE, v. 1, p. 1-12, 2017.

. Práticas de Exclusão em Ambiente Escolar. 1. ed. São Paulo: Unesp, 2017.

SILVA, Marcio Antonio da; MIARKA, Roger. Geni, a Pesquisa em [E]educação [M]matemática e o Zepelim. PERSPECTIVAS DA EDUCAÇÃO MATEMÁTICA, v. 10, p. 752-767, 2017.

SILVA, Tomaz Tadeu da. Identidade e diferença: impertinências. Educação e Sociedade, n.79, p. 65-66, 2002.

SMOLE, Kátia Stocco; DINIZ, Maria Ignez; MILANI, Estela. Jogos de matemática de 60 a 9 ano. Porto Alegre: Artmed, 2007.

SOUZA, Antonio Carlos Carrera de. O que pode a Educação Matemática? Linha Mestra (Associação de Leitura do Brasil), v. VII, p. 211-215, 2013. 